\title{
Gateway Lunar Habitat Modules as the Basis for a Modular Mars Transit Habitat
}

\author{
David Smitherman \\ NASA Marshall Space Flight Center \\ ED04 Advanced Concepts Office \\ Huntsville, AL 35812 \\ david.smitherman@nasa.gov
}

\author{
Andrew Schnell \\ NASA Marshall Space Flight Center \\ ST24 Science and Technology Office \\ Huntsville, AL 35812 \\ andrew.schnell@nasa.gov
}

\begin{abstract}
This paper provides a summary of the results from a recent concept study of various configurations for a Mars Transit Habitat. The designs considered are composed of modules based on published contractor concepts proposed for the lunar Gateway through NASA's NextSTEP program. Using these Gateway concepts as a starting point for the design of a Mars Transit Habitat has potential advantages. Both Gateway and Mars Transit Habitats will have similar requirements for long-term operations in deep space, autonomous and remote operations when the crew is not onboard, and similar requirements for transferring crew to and from a planetary surface-the Moon and Mars respectively. The contractor designs for Gateway were traded against a monolithic transit habitat previously proposed by NASA's Mars Integration Group. In addition, these concepts were considered for a "shakedown" mission for the transit habitat hardware in cislunar space to build confidence in new systems, including the advanced environmental control and life support systems needed for Mars missions. The results presented include overall vehicle configurations, mass, and volume estimates for the selected design concepts. Two concepts using large expandable modules are identified as leading candidates for a Mars Transit Habitat and the remaining elements are identified as representative of the habitable pressure vessels needed for safe haven configurations, logistics modules, surface habitats, rovers, and descent and ascent crew cabins in the overall Mars Architecture.
\end{abstract}

\section{TABLE OF ConTENTS}

1. INTRODUCTION 1

2. GATEWAY AND MARS TRANSIT HABITATS .......... 1 3. OTHER APPLICATIONS TO MARS MISSIONS......... 5 4. MASS AND VOLUME.................................................... 6 5. FINDINGS AND RECOMMENDATIONS........................ 7 APPENDICES......................................................... 8

A. MASS PRopertieS..................................................... 8

B. ABBREVIATIONS \& ACRONYMS .......................... 11 ACKNOWLEDGEMENTS ................................................ 12

REFERENCES........................................................... 12

BIOGRAPHY ........................................................................ 12

\section{INTRODUCTION}

The Gateway is an important next-step toward future human missions to Mars. It will provide an outpost in deep space for development and testing of technologies and systems critical for safe operations in deep space, and for operations between Gateway in lunar orbit, and the surface. The combination of Gateway and these missions to the Moon will demonstrate the basic operational capabilities for all Mars systems and provide a means to utilize cost-effective, reusable vehicles for ongoing missions to both the Moon and Mars. To confirm the extensibility of Gateway to future Mars missions, this study developed conceptual designs for several Mars Transit Habitat configurations utilizing the proposed contractor habitat modules from Gateway as the primary pressure vessel volumes. Assumptions for NASA's baseline design used in the comparison were taken from the latest refinement study technical paper "Transit Habitat Design for Mars Exploration" [1], which describes the vehicle designs for a Mars Transit Habitat that can support a crew of four for up to 1,200 days in a journey from Earth to Mars with a safe return.

\section{Gateway and Mars Transit Habitats}

Four configurations were developed from the NextSTEP contractor concepts to compare with the latest MIG Baseline Configuration concept for the Mars Transit Habitat. These configurations use habitat modules proposed by Bigelow Aerospace, Sierra Nevada, the Boeing Company and Lockheed Martin, and Northrop Grumman. [2] The MIG Baseline Configuration outfitting mass details were input into a habitat sizing tool under development in the Advanced Concepts Office (ACO) and calibrated to include the internal systems required for a Mars Transit Habitat. Each of the alternate contractor configurations were then sized using the same settings, but varying only the parameters unique to each of the contractor modules. This ensured that a reasonable comparison between configurations was being made without having to delve into proprietary data from each contractor.

\section{MIG Baseline Configuration}

The MIG Baseline Configuration, shown in Figures 1, is a single, large habitat module attached to a Hybrid propulsion 
vehicle. The habitat has an airlock on the forward dome with a docking mechanism for attachment to the Gateway and crew vehicles. The airlock is utilized for EVA outside of the spacecraft if needed, and a robotic arm that can walk the length of the vehicle is provided to assist with EVAs or perform maintenance remotely. There are two radial docking ports in the side of the large module, and two windows. The surface of the habitat module is covered with micrometeoroid shielding, radiator panels, and thermal protection. The aft skirt encloses a small propulsion system with forward and aft thrusters to assist with alignment and docking operations. The aft end is mated to a Hybrid propulsion stage which includes storable propellants, deployable radiators, and large solar panels to collect solar energy for the solar electric propulsion (SEP) and habitat power systems. Alternate chemical propulsion systems are possible, but the Hybrid SEP system is shown for consistency in all configurations.

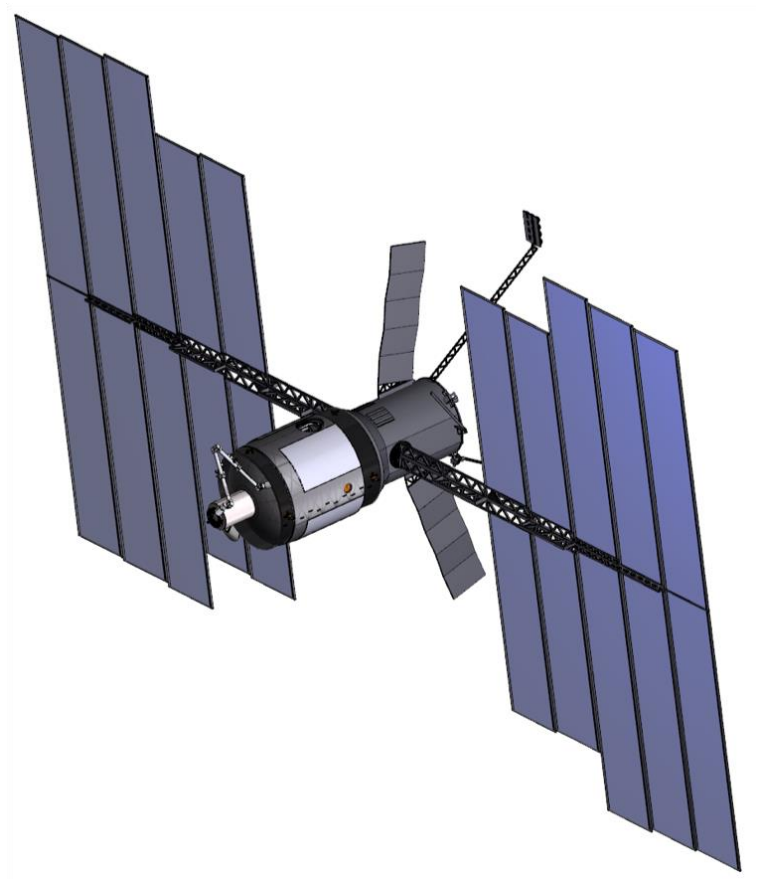

Figure 1. The MIG Baseline Configuration for a Mars transit habitat concept used for this study. [1]

An interior view is illustrated in Fig. 2, with a cross-section showing two deck levels. The lower deck includes all the primary crew work areas and the upper deck includes crew quarters wrapped with stowage to maximize radiation protection. The internal volumes of the forward and aft end domes are used for life support and vehicle systems, and the airlock attached to the external forward dome provides for EVA operations.

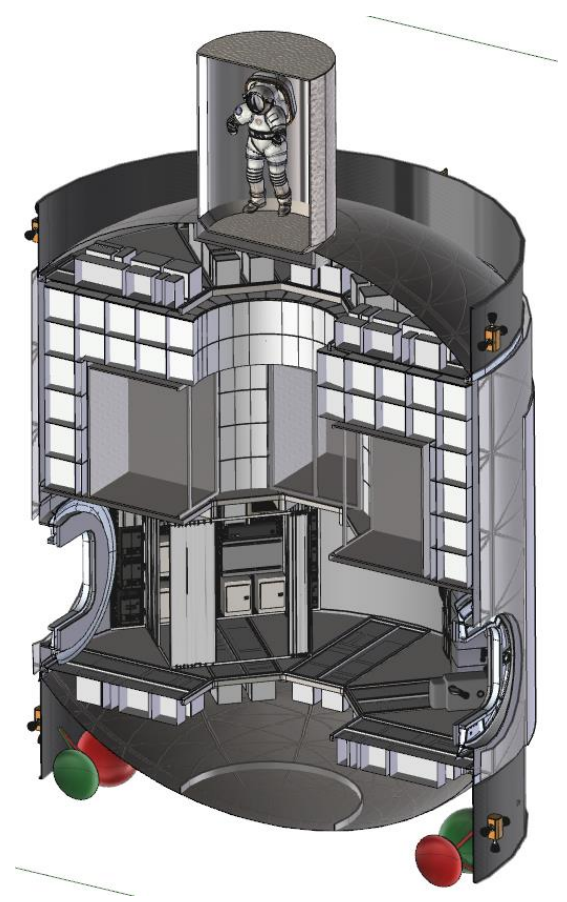

Figure 2. The MIG Baseline interior layout used to help drive requirements for all configurations. $[1,3]$

The detailed outfitting requirements and mass for the MIG Baseline Configuration were set based on a 2018 refinement study described in the technical paper, "Transit Habitat Design for Mars Exploration". [1] The details were used to set up the ACO habitat sizing tool for the baseline configuration, resulting in a habitat mass of about 55.5 metric tons $(\mathrm{mT})$ with a pressurized volume of about 317 cubic meters $\left(\mathrm{m}^{3}\right)$. The same settings were then used for all the remaining configurations, varying only the particulars for the contractor proposed modules. More details on the mass of each configuration can be found in Appendix A; and Section 4 on Mass and Volume provides a comparison of the configurations, and a description of a $10 \mathrm{mT}$ mass reduction approach to $45 \mathrm{mT}$ for the baseline configuration from the referenced 2018 refinement study.

\section{Bigelow Aerospace}

The Bigelow Aerospace modules for Gateway, shown in Fig. 3 , are expandable modules that provide $330 \mathrm{~m}^{3}$ of livable volume each. [2] Only one of these modules is required for a Mars Transit Habitat as shown in Fig. 4. The module includes a forward rigid pressure vessel volume for an airlock, docking ports and propulsion for docking operations. The aft structure is attached to the Hybrid propulsion vehicle. Habitat mass was determined to be about $58 \mathrm{mT}$ at a volume of about $330 \mathrm{~m}^{3}$ as stated. The higher mass for this configuration is triggered primarily by unknowns in the structural design and interior layout but is not considered significant. In general, the interior layout should accommodate all the mechanical systems in the central structural core and the expanded volume should be useable for open space and stowage. 


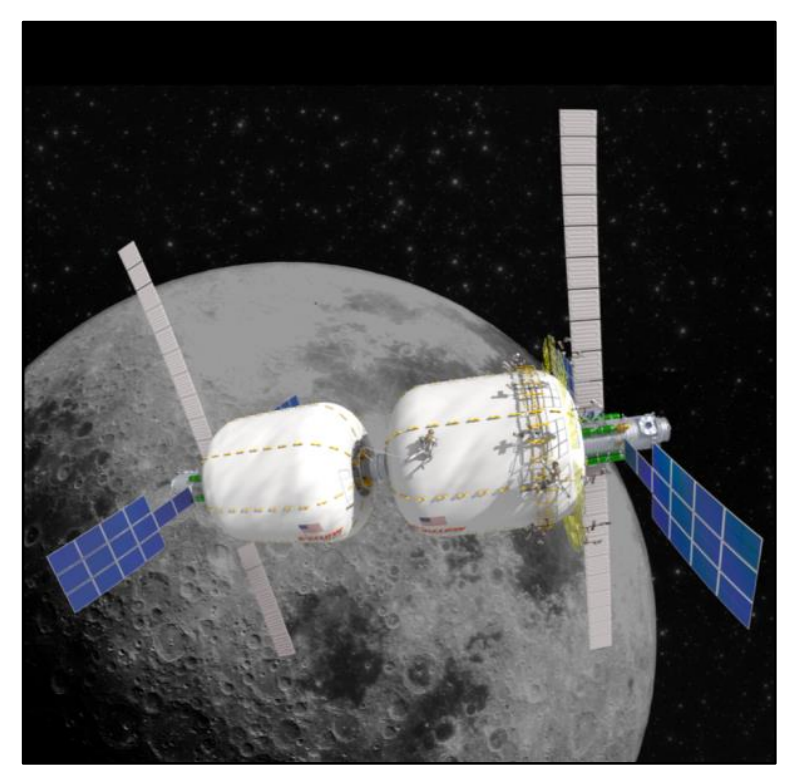

Figure 3. Bigelow Aerospace concept for Gateway. [2]

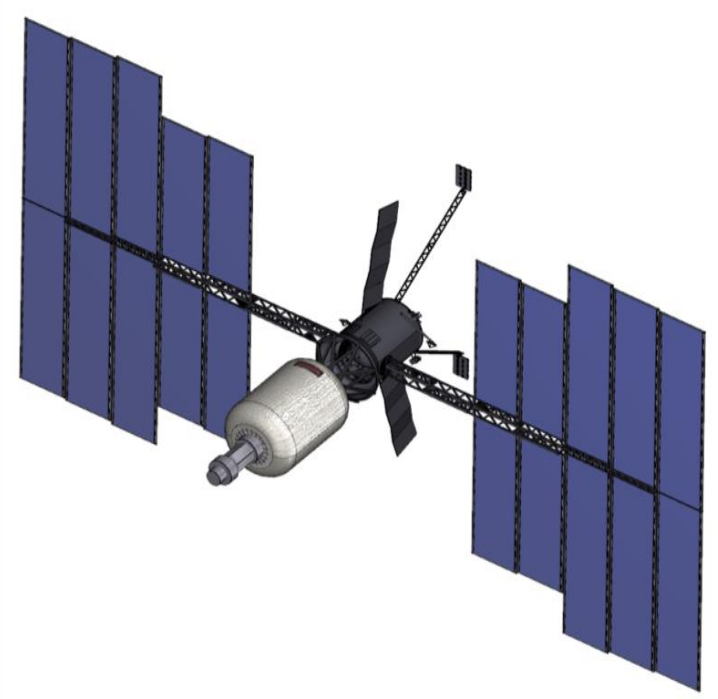

Figure 4. NASA Mars Transit Vehicle concept utilizing a Bigelow Aerospace expandable habitat module.

\section{Sierra Nevada}

The Sierra Nevada Large Inflatable Fabric Environment (LIFE) habitat shown in the Gateway configuration, Fig. 5, is similar to the Bigelow Aerospace module, in that it is designed for launch in a compact, deflated configuration and then inflated in space. The benefit of inflatables is that their final configuration is capable of providing much larger living volume than traditional rigid structures, which are limited in size by the payload volume of the rocket used for launch. The LIFE module shown inflates to about $8 \mathrm{~m}$ in diameter and simulates three floors of living area. [2] For the Mars Transit Habitat shown in Fig. 6, one LIFE module is used along with an attached logistics module to bring the total pressurized volume up to $324 \mathrm{~m}^{3}$. The forward end has docking ports, an airlock, and propulsion similar to the Bigelow Aerospace configuration resulting in a mass of about $61 \mathrm{mT}$. Like the Bigelow configuration, the mass growth is not considered significant, and the attached logistics module provides for some interesting options. For example, in a typical Mars mission there are about 300 - 500 days of logistics on board the habitat that are no longer needed when the crew returns from the surface of Mars. In this configuration it would be possible to leave this logistics in Mars orbit for future missions using the attached module. Another option is to use the logistics module as a 30-day safe haven for protection of the crew in the event of pressure loss in the inflatable structure. Various options for safe havens have been described in a previous technical paper for Mars Transit Habitats. [4]

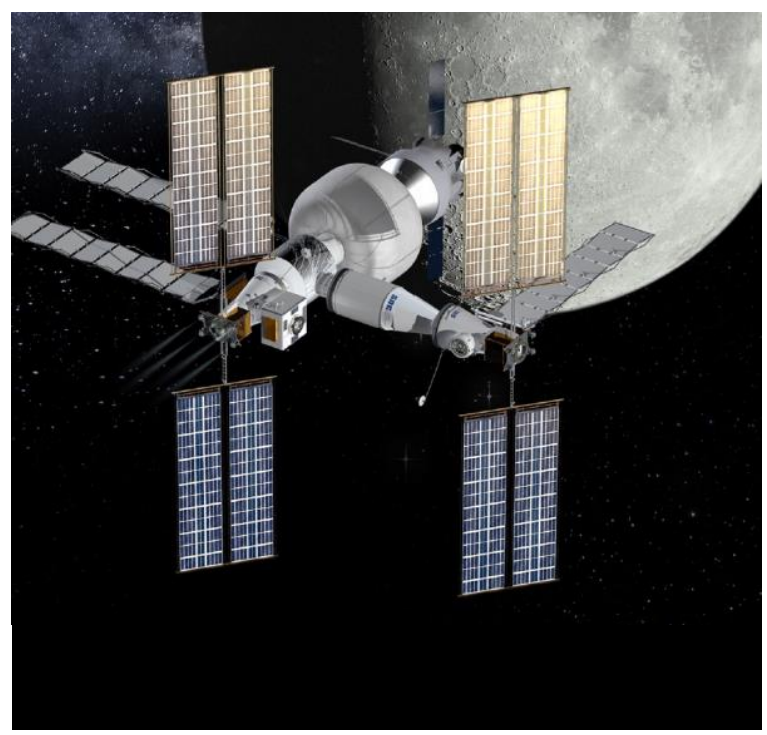

Figure 5. Sierra Nevada concept for Gateway. [2]

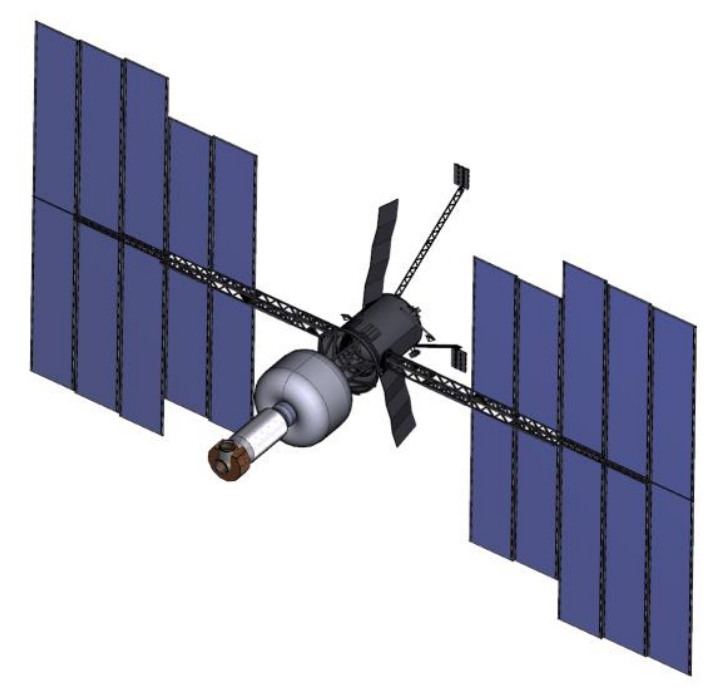

Figure 6. NASA Mars Transit Vehicle concept utilizing a Sierra Nevada inflatable habitat module. 


\section{The Boeing Company and Lockheed Martin}

The Boeing Company and Lockheed Martin configurations for Gateway shown in Figures 7 and 8 respectively, use proven hardware based on module designs from the International Space Station (ISS). [2] The configurations include habitat modules, nodes, and airlocks with pressurized volumes up to about $75 \mathrm{~m}^{3}$ per module. The Mars Transit Habitat design based on their designs, Fig. 9, uses five modules to bring the total pressurized volume up to about $384 \mathrm{~m}^{3}$ with a resulting mass of about $76.7 \mathrm{mT}$. The mass growth for this configuration is significant and is caused by the increase in the number of modules and the resulting structural mass from duplicate systems. Regardless, several options and opportunities present themselves with this configuration. For example, the mass growth may make it difficult to use a Hybrid SEP propulsion system, so chemical and nuclear propulsion options might be preferred. In addition, one of the modules could be used for logistics and dropped off in Mars orbit, and safe haven configurations could be incorporated, as described in the Sierra Nevada configuration above making the overall system more robust.

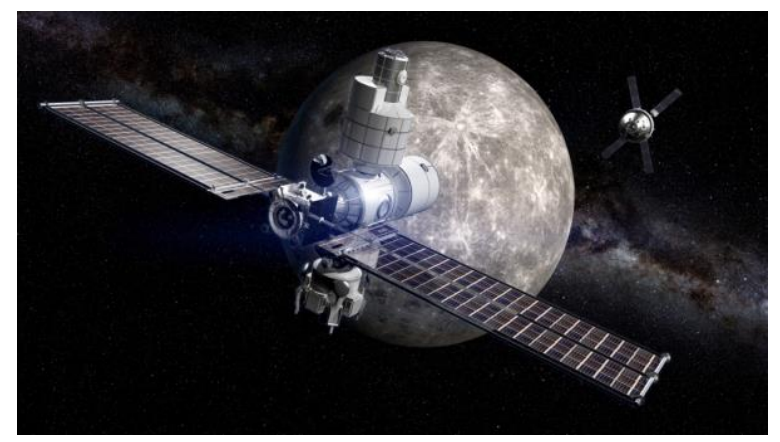

Figure 7. The Boeing Company concept for Gateway. [2]

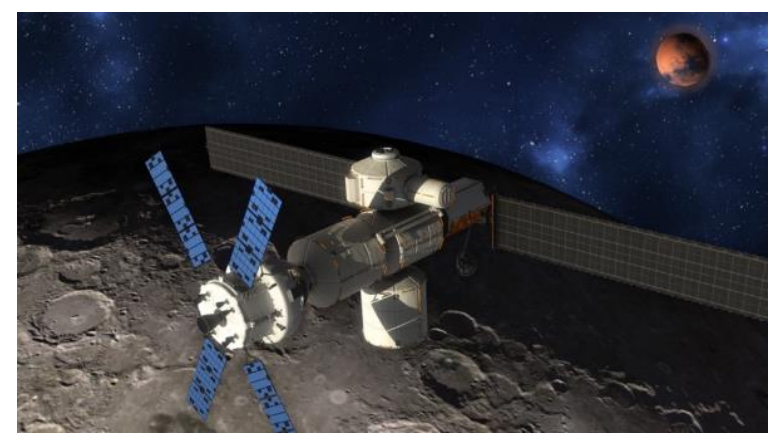

Figure 8. Lockheed Martin concept for Gateway. [2]

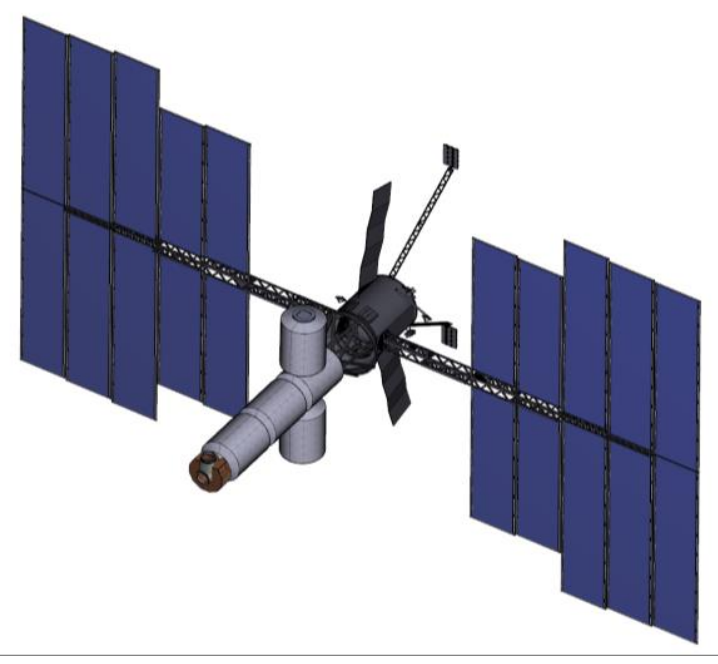

Figure 9. NASA Mars Transit Vehicle concept utilizing the Boeing Company and Lockheed Martin habitat modules.

\section{Northrop Grumman}

Northrop Grumman's Gateway configuration shown in Fig. 10 uses a module similar to an ISS node and variations on the company's Cygnus module that delivers supplies to the ISS. [2] The Mars Transit Habitat shown in Fig. 11 utilizes two ISS derived nodes and five Cygnus modules to provide a pressurized volume of about $348 \mathrm{~m}^{3}$ with a resulting mass of about $81.4 \mathrm{mT}$. Like the previous configuration, the increase in the number of modules significantly increases the mass. However, the same opportunities for alternate propulsion systems along with incorporating the other feature that multiple modules provide for logistics delivery and safe haven configurations do offer additional considerations.

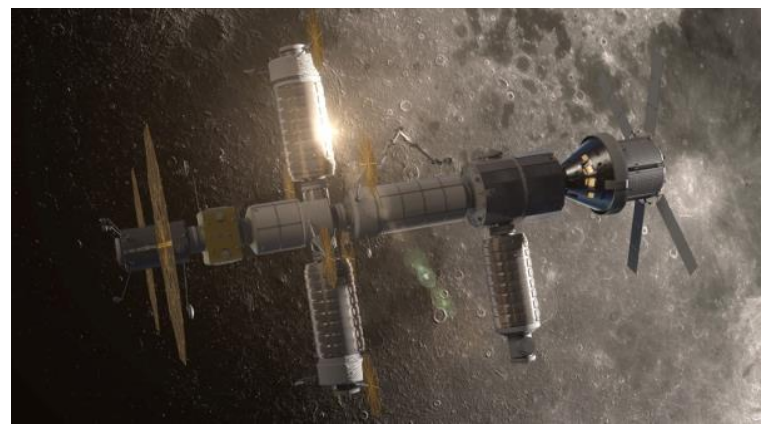

Figure 10. Northrop Grumman concept for Gateway. [2] 


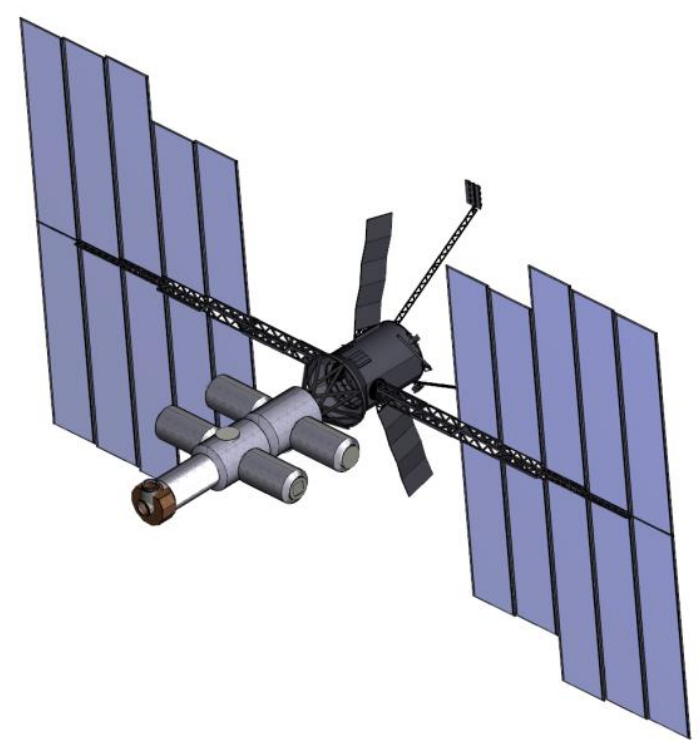

Figure 11. NASA Mars Transit Vehicle concept utilizing Northrop Grumman habitat modules.

\section{OTher APPliCATions to MARS MISSIONS}

There are other applications of Gateway configurations shown above to the Mars architecture in addition to the Mars Transit Habitat. These include the crew volumes required for various in-space and Mars surface vehicle systems.

\section{Gateway}

The overall Mars mission begins and ends at Gateway. Gateway is the servicing hub that makes reusability possible to support ongoing missions to both the Moon and Mars. Its establishment in the overall architecture is critical to the longterm economic viability of both government and commercial missions, and the development of high reliability for crew safety and success for all deep space missions.

\section{Mars Shakedown Cruise}

A shakedown cruise is often described as one of the first steps prior to departure on the first mission to Mars to test all of the systems over a one-year period with the crew onboard. This duration basically simulates the transit time to or from Mars. The shakedown cruise should ideally be performed in the final vehicle configuration; however, alternatives are possible. As long as the crew is living onboard in the simulated isolation of transit with all of the required systems for life support then this demonstration should be possible. This means that any of the Mars Transit Habitat vehicle configurations described above are feasible. With an appropriate propulsion system, a shakedown cruise should be possible to traverse a variety of distant Earth-Moon orbits for exploration, demonstration, and possible servicing activities. Examples include: distant retrograde orbits (DRO) for future outpost destinations; geosynchronous Earth orbit (GEO) for satellite servicing; Earth-Sun Lagrange orbits (ESL2) for science instrument servicing; and near rectilinear orbits (NRO) around the Moon to simulate better access to additional lunar surface destinations.

\section{Surface Habitats}

Surface habitats for Mars missions typically provide support for a crew of four over 300 - 500 days. The complete surface habitat is usually formed with several modules that require off-loading from a lander onto a mobility platform and transported to a base camp site for berthing to other modules. The base camp is usually about a kilometer or more away from the landing area to protect the habitats from debris scatter. Typical configurations for the surface habitats use ISS modules designed for living quarters, surface labs, nodes, and airlocks, with new logistics modules attached for each crew mission to the surface habitat. The module size and configurations provided by the Boeing Company and Lockheed Martin concepts for Gateway are similar in size and design to meet the surface habitat requirements.

\section{Logistics Modules}

Logistics delivery to the surface of Mars will be required for every mission to support four crew in the $300-500$ day range. The module will be delivered in a similar manner as the habitat modules, which includes off-loading from the lander, transport to the base camp, and docking to the habitat. Some scenarios have combined this delivery with the crew delivery to the surface for each mission too. In general, a 300day mission could probably utilize the volume from the smaller Cygnus modules provided by Northrop Grumman, and the 500-day missions would likely require the larger volume of the ISS-derived modules from the Boeing Company and Lockheed Martin.

Cabins for the Descent Vehicle, Pressurized Rover, and Ascent Vehicle

The cabin sizes for descent to the surface from Mars orbit, roving on the surface, and ascent from the surface back to the Mars Transit Habitat have similar volumes that can probably be accommodated by the smaller Cygnus diameter modules from the Northrop Grumman designs. In general, each of these modules can be designed to support four crew for about a week or two. 


\section{MASS AND Volume}

The volume for each of the configurations was held closely to the MIG Baseline Configuration of $317 \mathrm{~m}^{3}$ with only moderate growth to account for standard module sizes and the additional systems and circulation needed for the configurations with multiple modules. A summary is provided in Fig. 12, showing the mass growth as the module sizes decrease and the number of modules required increase to accommodate the total volume needed. In general, the mass growth was found in the duplicate structures and systems required for multiple modules. These included duplicate docking mechanisms, end cone structures, utility interconnects, and support systems required for each pressure vessel. The configurations using multiple small modules will likely require a division of the life support system into two modules with air regeneration systems in one and water recycling systems in another.

\section{Mass Adjustments}

As previously mentioned, the baseline mission for all the configurations is designed to support four crew for 1,200 days. This length of time is not required for every mission, as indicated in Table 1 where mission durations vary from 1,043 to 1,047 days. The reduction in the number of crew days has a significant impact on mass, making it possible to reduce the total mass to about $45 \mathrm{mT}$, which is thought to be a reasonable limit for the Hybrid SEP propulsion system. More details on how this was accomplished and the alternatives for higher mass configurations are available in the refinement study technical paper. [1] If longer durations and alternate configurations are used as indicated in Fig. 12, then alternate propulsion systems are possible. These include adding kick stages for the initial trans-Mars-injection burn to boost the Hybrid SEP system, or using alternate high thrust from chemical and nuclear thermal propulsion (NTP) systems.

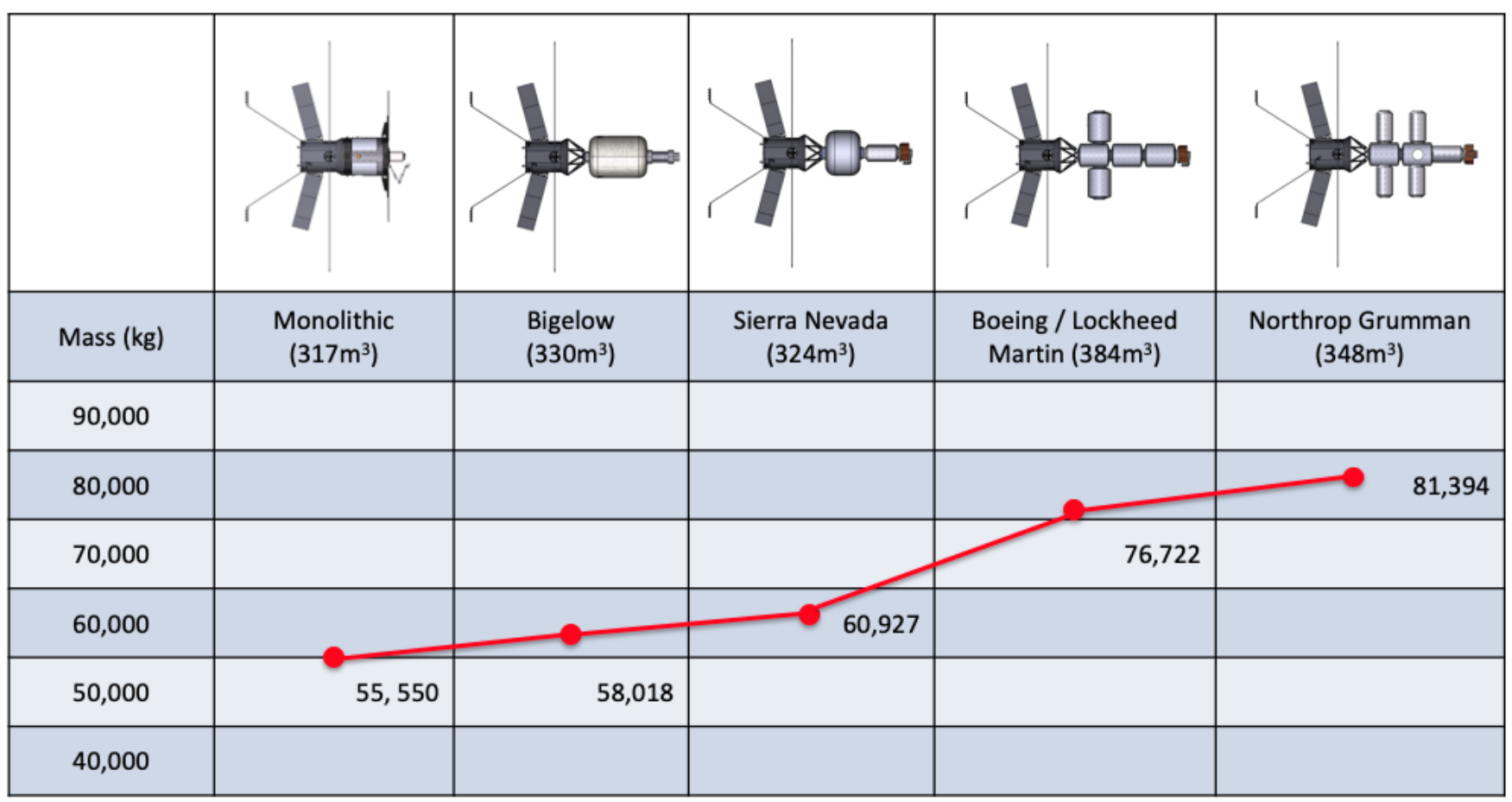

Figure 12. Summary of the mass and volume for the Mars Transit Habitat configurations.

Table 1. Variation in the Mars Transit Habitat departure mass.

\begin{tabular}{|l|c|c|c|c|c|}
\cline { 3 - 6 } \multicolumn{2}{c|}{} & Mars Orbital & Mars Surface \#1 & Mars Surface \#2 & Mars Surface \#3 \\
\hline Duration & days & 1,073 & 1,073 & 1,073 & 1,047 \\
\hline Earth Departure Consumables Mass & $\mathbf{k g}$ & $\mathbf{2 0 , 9 8 3}$ & $\mathbf{2 0 , 9 8 3}$ & $\mathbf{2 0 , 9 8 3}$ & $\mathbf{2 0 , 6 5 7}$ \\
\hline $\begin{array}{l}\text { Manufacturer's Empty Mass* } \\
\text { (Reduced) }\end{array}$ & $\mathbf{k g}$ & $\mathbf{2 1 , 2 5 6}$ & $\mathbf{2 1 , 2 5 6}$ & $\mathbf{2 1 , 2 5 6}$ & $\mathbf{2 1 , 2 5 6}$ \\
\hline Fixed Operational Items & $\mathbf{k g}$ & $\mathbf{2 , 9 0 2}$ & $\mathbf{2 , 9 0 2}$ & $\mathbf{2 , 9 0 2}$ & $\mathbf{2 , 9 0 2}$ \\
\hline \hline Earth Departure Mass & $\mathbf{k g}$ & $\mathbf{4 5 , 1 4 1}$ & $\mathbf{4 5 , 1 4 1}$ & $\mathbf{4 5 , 1 4 1}$ & $\mathbf{4 4 , 8 1 5}$ \\
\hline
\end{tabular}




\section{FINDINGS AND RECOMMENDATIONS}

The authors of this paper set out to examine the extensibility of the planned Gateway outpost to future Mars missions, in particular to the Mars Transit Habitat. It was found that any of the Gateway configurations proposed so far do have significant extensibility to parts of the Mars architecture and that some are particularly applicable to the Mars Transit Habitat.

\section{Configurations}

The best Mars Transit Habitat configurations include the original monolithic MIG Baseline Configuration, the Bigelow Aerospace inflatable module, and the Sierra Nevada LIFE inflatable module with one attached logistics element. All four configurations evaluated are possible for a shakedown cruise given adequate volume and propulsion capabilities to demonstrate key life support systems. In addition, the Boeing Company, Lockheed Martin, and Northrop Grumman-proposed Gateway configurations have applicability to all the other modules required for the Mars architecture, including surface habitats, logistics, descent and ascent vehicles, and surface pressurized rovers. Multiple modules offered advantages too, including the possibility of dropping off unused logistics modules in Mars orbit for use in future missions, and the development of safe haven configurations to protect the crew from pressure loss in a single module.

\section{Propulsion}

Although the Hybrid SEP propulsion system is featured in this paper, there are at least three propulsion systems under consideration for the Mars Transit Habitat vehicles. A chemical system using cryogenic oxygen and methane (LOX/CH4), a NTP system using cryogenic hydrogen, and a Hybrid SEP propulsion system using storable propellants with conventional and solar electric thrusters. All three systems have advantages and disadvantages. For example, the LOX/CH4 system requires cryogenic storage to keep the propellants from boiling off, which adds mass and complexity to the system, but provides high thrust for fast transit times. The NTP system has more complex cryogenic hydrogen storage issues and radiation concerns from the nuclear reactor, but it too provides fast-possibly the fastest - transit times. The Hybrid SEP system uses storable propellant so there are no propellant storage issues, but a practical system may be limited to a $45 \mathrm{mT}$ habitat mass, and the SEP system yields slower transit times between Earth and Mars compared to the other two systems. For Mars missions, the slower transit time can mean less time on the surface of Mars and more time in transit between the Earth and Mars where there is more exposure to space radiation.

\section{Gateway Requirements Considerations}

In conclusion, several recommendations for the Gateway outpost are apparent from this extensibility study. They are as follows:

\section{Large Volume}

An attached, inflatable module should be included in the Gateway architecture to demonstrate that large volume inflatables are feasible and can be constructed and outfitted to survive the rigors of the space environment on longduration missions. The alternatives are a large volume aluminum pressure vessel that is not in the current architecture proposals, or multiple smaller pressure vessels that would increase mass.

\section{Advanced Life Support}

Gateway development needs to demonstrate the advanced regenerative life support systems needed for ongoing operations. This will prove that the advanced life support planned for Mars missions can actually meet the reliability and mass projections needed for these long duration missions. These systems should be added to the architecture even if the large modules needed are not provided and the life support system has to be divided into separate modules for air regeneration and water recycling.

\section{Docking and Berthing}

A finding in the study not previously mentioned is a recommendation for use of the common berthing mechanism (CBM) instead of or in addition to the NASA docking systems (NDS) currently planned as the international standard for the Gateway assembly. There is no significant difference in mass between the two systems, and in fact, it may be possible to reduce the mass for some modules like the Cygnus and ISS derived modules already designed for the CBM. The larger CBM system provides a much larger passthrough for logistics and systems, better feed-throughs for utilities, and it provides a system that could be adaptable to surface habitat berthing interfaces where step-through hatches are possible in the low gravity environment as opposed to crawling through hatches on hands and knees. Modifications to the CBM would be required where autonomous docking procedures are required.

\section{Safe Havens}

Gateway should consider safe haven configurations and how these features could be adopted in the design as the Gateway configuration grows. Current plans for pressure loss include retreat to the Orion for emergency return. Alternatives could be considered if the modules were designed with safe haven requirements in place. 


\section{APPENDICES}

\section{A. Mass Properties}

The mass properties, design constraints, and parameters for each of the configurations is provided in this appendix for reference. The following should be noted: a) the "Launch Mass" indicated cannot be launched on one launch vehicle in the multi-module configurations and excludes some outfitting logistics; b) the "Outfitted Mass" is the total mass of the habitat element for the Mars Transit Habitat vehicle and does not include the Hybrid SEP propulsion element shown in the graphic representation; c) the "3.0 Power" system does not include the large solar arrays that are part of the Hybrid SEP propulsion element; d) the "6.0 Radiation Protection" is assumed to be provided by the packaging of logistics around the crew quarters; e) the "Actual Estimated Loss of Mission" estimated at $2.25 \%$ is based on a desired mission success rate of $98 \%$ and is calculated based primarily on the number of spares and their risk of failure - higher success rates are possible, but will drive up mass significantly; and f) mass estimates are based on high technology readiness levels from proven flight hardware where possible.

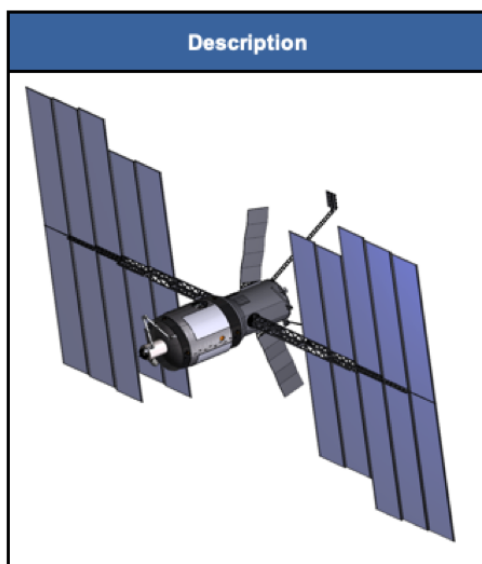

Mars Tranist Habitat w/ Hybrid Propulsion

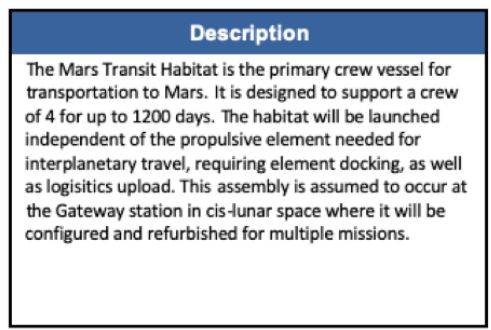

\begin{tabular}{|lrr|}
\hline \multicolumn{3}{|c|}{ Design Constraints / Parameters } \\
\hline Maximum Crew Size & \multicolumn{3}{c|}{4} \\
Max Crewed Mission Duration & 1,200 & days \\
Destination & Mars 1 Sol & Orbit \\
Pressurized Volume & 316.85 & $\mathrm{~m}^{3}$ \\
Systems Volume & 132.90 & $\mathrm{~m}^{3}$ \\
Stowage Volume & 99.13 & $\mathrm{~m}^{3}$ \\
Habitable Volume & 84.81 & $\mathrm{~m}^{3}$ \\
Operating Pressure & 101.30 & $\mathrm{kPa}$ \\
Oxygen Fraction & 21.00 & $\%$ \\
Life Support Closure - Water & Closed & \\
Life Support Closure - Air & Closed & \\
Habitat Structure & Aluminum & \\
Habitat Overall Length & 11.50 & $\mathrm{~m}$ \\
Habitat Diameter & 7.20 & $\mathrm{~m}$ \\
Radiation Protection & 0.00 & $\mathrm{~kg}$ \\
EVA Capability & 10 & \\
Crew per EVA & 2 & \\
RCS Engine Type & $440,90,30$ & $\mathrm{~N}$ \\
RCS Propellant & Hydrazine, N2O4 \\
Power Generation & 26.64 & $\mathrm{~kW}$ \\
Energy Storage & 5.93 & $\mathrm{~kW}$ \\
Keep Alive Power (uncrewed) & 5.93 & $\mathrm{~kW}$ \\
Solar array area & 242.89 & $\mathrm{~m}$ \\
Thermal Radiator Area & 100.33 & $\mathrm{~m}^{2}$ \\
Actual Estimated Loss of Mission & $2.25 \%$ & \\
Average TRL & 7.87 & \\
Mass Growth Allowance (MGA) & $15.54 \%$ & \\
Project Management Reserve (PMR) & $0 \%$ & \\
\hline
\end{tabular}

\begin{tabular}{|c|c|c|c|}
\hline & Mass Breakdown & $\begin{array}{l}\text { Launch } \\
\text { Mass }\end{array}$ & $\begin{array}{l}\text { Outfitted } \\
\text { Mass }\end{array}$ \\
\hline System & & (kg) & (kg) \\
\hline 1.1 & Structures & 9,225 & 9,225 \\
\hline 2.0 & Propulsion & 1,573 & 1,573 \\
\hline 3.0 & Power & 874 & 874 \\
\hline 4.0 & Avionics & 1,621 & 1,621 \\
\hline 5.0 & Thermal & 2,165 & 2,165 \\
\hline 6.0 & Radiation Protection & - & - \\
\hline 7.0 & ECLSS & 4,142 & 4,142 \\
\hline 8.0 & Crew Systems & 3,254 & 3,254 \\
\hline 9.0 & EVA & 1,116 & 1,116 \\
\hline 10.0 & Research & 764 & 764 \\
\hline 11.0 & Robotics & 943 & 943 \\
\hline Dry Mass & & 25,676 & 25,676 \\
\hline 12.0 & Stowed Provisions & - & 12,935 \\
\hline 13.0 & Consumables & - & 15,319 \\
\hline 14.0 & Nonpropellant Fluids & 70 & 70 \\
\hline Inert Mas & & 70 & 28,324 \\
\hline Subtotal & & 25,746 & 54,001 \\
\hline & Attached Payloads & & \\
\hline & Propulsion Stage & & \\
\hline 15.0 & Propellant & 1,396 & 300 \\
\hline 16.0 & Payload Launch Adapter & 1,772 & \\
\hline 17.0 & In-Space Stage Adapter & 1,249 & 1,249 \\
\hline $0.0 \%$ & Project Mgt. Reserve & - & - \\
\hline \multicolumn{2}{|c|}{ Total Gross Mass } & 30,163 & 55,550 \\
\hline
\end{tabular}

Figure A-1. NASA MIG Baseline Configuration derived Mars Transit Habitat mass summary. 


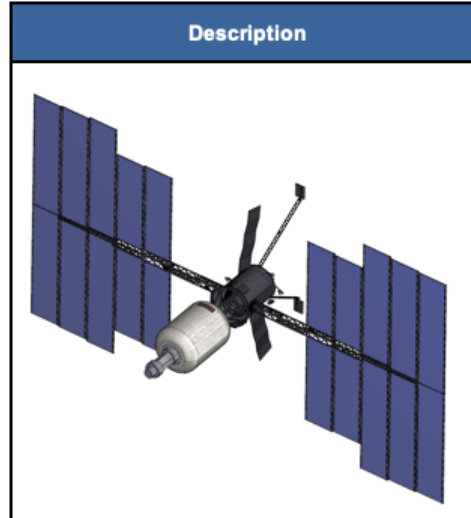

Bigelow Module w/ Hybrid Propulsion

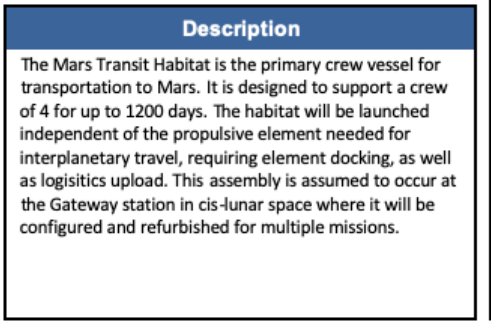

\begin{tabular}{|c|c|}
\hline \multicolumn{2}{|c|}{ Design Constraints / Parameters } \\
\hline Maximum Crew Size & 4 \\
\hline Max Crewed Mission Duration & 1,200 days \\
\hline Destination & Mars 1 Sol Orbit \\
\hline Pressurized Volume & $330.00 \mathrm{~m}^{3}$ \\
\hline Systems Volume & $129.30 \mathrm{~m}^{3}$ \\
\hline Stowage Volume & $99.18 \mathrm{~m}^{3}$ \\
\hline Habitable Volume & $101.52 \mathrm{~m}^{3}$ \\
\hline Operating Pressure & $101.30 \mathrm{kPa}$ \\
\hline Oxygen Fraction & $21.00 \%$ \\
\hline Life Support Closure - Water & Closed \\
\hline Life Support Closure - Air & Closed \\
\hline Habitat Structure & Inflatable \\
\hline Habitat Length & $13.70 \mathrm{~m}$ \\
\hline Habitat Diameter & $6.70 \mathrm{~m}$ \\
\hline Radiation Protection & $0.00 \mathrm{~kg}$ \\
\hline EVA Capability & 10 \\
\hline Crew per EVA & 2 \\
\hline RCS Engine Type & $440,90,30$ \\
\hline RCS Propellant & Hydrazine, N2O4 \\
\hline Power Generation & $26.70 \mathrm{~kW}$ \\
\hline Energy Storage & $5.96 \mathrm{~kW}$ \\
\hline Keep Alive Power (uncrewed) & $5.96 \mathrm{~kW}$ \\
\hline Solar array area & $243.41 \mathrm{~m}^{2}$ \\
\hline Thermal Radiator Area & $100.51 \mathrm{~m}^{2}$ \\
\hline Actual Estimated Loss of Mission & $2.25 \%$ \\
\hline Average TRL & 8.39 \\
\hline Mass Growth Allowance (MGA) & $18.49 \%$ \\
\hline Project Management Reserve (PMR) & $0.00 \%$ \\
\hline
\end{tabular}

\begin{tabular}{|c|c|c|c|}
\hline & Mass Breakdown & $\begin{array}{c}\text { Launch } \\
\text { Mass }\end{array}$ & $\begin{array}{l}\text { Outfitted } \\
\text { Mass }\end{array}$ \\
\hline System & & (kg) & $(\mathrm{kg})$ \\
\hline 1.1 & Structures & 10,992 & 10,992 \\
\hline 2.0 & Propulsion Bus & 1,875 & 1,875 \\
\hline 3.0 & Power & 1,207 & 1,207 \\
\hline 4.0 & Avionics & 1,621 & 1,621 \\
\hline 5.0 & Thermal & 1,911 & 1,911 \\
\hline 6.0 & Radiation Protection & - & - \\
\hline 7.0 & ECLSS & 4,393 & 4,393 \\
\hline 8.0 & Crew Systems & 3,254 & 3,254 \\
\hline 9.0 & EVA & 1,116 & 1,116 \\
\hline 10.0 & Research & 764 & 764 \\
\hline 11.0 & Robotics & 943 & 943 \\
\hline Dry Mass & & 28,076 & 28,076 \\
\hline 12.0 & Stowed Provisions & - & 12,935 \\
\hline 13.0 & Consumables & - & 15,319 \\
\hline 14.0 & Nonpropellant Fluids & 83 & 83 \\
\hline Inert Mas & & 83 & 28,338 \\
\hline Subtotal & & 28,159 & 56,413 \\
\hline & Attached Payloads & & \\
\hline & Propulsion Stage & & \\
\hline 15.0 & Propellant & 1,664 & 300 \\
\hline 16.0 & Payload Launch Adapter & 1,937 & \\
\hline 17.0 & In-Space Stage Adapter & 1,304 & 1,304 \\
\hline $0.0 \%$ & Project Mgt. Reserve & - & - \\
\hline \multicolumn{2}{|c|}{ Total Gross Mass } & 33,065 & 58,018 \\
\hline
\end{tabular}

Figure A-2. Bigelow Aerospace derived Mars Transit Habitat mass summary.

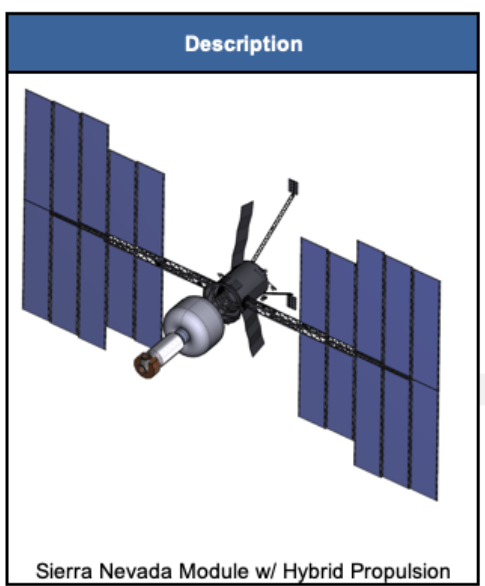

Description

The Mars Transit Habitat is the primary crew vessel for transportation to Mars. It is designed to support a crew of 4 for up to 1200 days. The habitat will be launched of 4 for up to 120 days. The habitat will be launched interplanetary travel, requiring element docking, as well as logisitics upload. This assembly is assumed to occur at the Gateway station in cis-lunar space where it will be configured and refurbished for multiple missions.

\begin{tabular}{|c|c|c|}
\hline \multicolumn{3}{|c|}{ Design Constraints / Parameters } \\
\hline Maximum Crew Size & 4 & \\
\hline Max Crewed Mission Duration & 1,200 & days \\
\hline Destination & Mars 1 Sol Ort & \\
\hline Pressurized Volume & 324.00 & $\mathrm{~m}^{3}$ \\
\hline Systems Volume & 135.98 & $\mathrm{~m}^{3}$ \\
\hline Stowage Volume & 100.72 & $\mathrm{~m}^{3}$ \\
\hline Habitable Volume & 87.30 & $\mathrm{~m}^{3}$ \\
\hline Operating Pressure & 101.30 & $\mathrm{kPa}$ \\
\hline Oxygen Fraction & 21.00 & $\%$ \\
\hline Life Support Closure - Water & Closed & \\
\hline Life Support Closure - Air & Closed & \\
\hline Habitat Structure & Inflatable & \\
\hline Habitat Overall Length & 15.30 & $\mathrm{~m}$ \\
\hline Habitat Diameter & 6.20 & $\mathrm{~m}$ \\
\hline Radiation Protection & 0.00 & $\mathrm{~kg}$ \\
\hline EVA Capability & 10 & \\
\hline Crew per EVA & 2 & \\
\hline RCS Engine Type & $440,90,30$ & $\mathrm{~N}$ \\
\hline RCS Propellant & Hydrazine, N2 & 204 \\
\hline Power Generation & 26.82 & kW \\
\hline Energy Storage & 6.02 & kW \\
\hline Keep Alive Power (uncrewed) & 6.02 & kW \\
\hline Solar array area & 244.46 & $\mathrm{~m}^{2}$ \\
\hline Thermal Radiator Area & 100.87 & $\mathrm{~m}^{2}$ \\
\hline Actual Estimated Loss of Mission & $2.25 \%$ & \\
\hline Average TRL & 8.39 & \\
\hline Mass Growth Allowance (MGA) & $15.25 \%$ & \\
\hline Project Management Reserve (PMR) & $0.00 \%$ & \\
\hline
\end{tabular}

Figure A-3. Sierra Nevada derived Mars Transit Habitat mass summary.

\begin{tabular}{|c|c|c|c|}
\hline & Mass Breakdown & $\begin{array}{l}\text { Launch } \\
\text { Mass }\end{array}$ & $\begin{array}{l}\text { Outfitted } \\
\text { Mass }\end{array}$ \\
\hline System & & $(\mathrm{kg})$ & $(\mathrm{kg})$ \\
\hline 1.1 & Structures & 14,843 & 14,843 \\
\hline 2.0 & Propulsion & 1,178 & 1,178 \\
\hline 3.0 & Power & 998 & 998 \\
\hline 4.0 & Avionics & 1,782 & 1,782 \\
\hline 5.0 & Thermal & 1,930 & 1,930 \\
\hline 6.0 & Radiation Protection & - & - \\
\hline 7.0 & ECLSS & 4,144 & 4,144 \\
\hline 8.0 & Crew Systems & 3,254 & 3,254 \\
\hline 9.0 & EVA & 1,116 & 1,116 \\
\hline 10.0 & Research & 764 & 764 \\
\hline 11.0 & Robotics & 943 & 943 \\
\hline Dry Mass & & 30,951 & 30,951 \\
\hline 12.0 & Stowed Provisions & - & 12,935 \\
\hline 13.0 & Consumables & - & 15,319 \\
\hline 14.0 & Nonpropellant Fluids & 52 & 52 \\
\hline Inert Mas & & 52 & 28,307 \\
\hline Subtotal & & 31,003 & 59,258 \\
\hline & Attached Payloads & & \\
\hline & Propulsion Stage & & \\
\hline 15.0 & Propellant & 1,045 & 300 \\
\hline 16.0 & Payload Launch Adapter & 2,136 & \\
\hline 17.0 & In-Space Stage Adapter & 1,370 & 1,370 \\
\hline $0.0 \%$ & Project Mgt. Reserve & - & - \\
\hline \multicolumn{2}{|c|}{ Total Gross Mass } & 35,554 & 60,927 \\
\hline
\end{tabular}




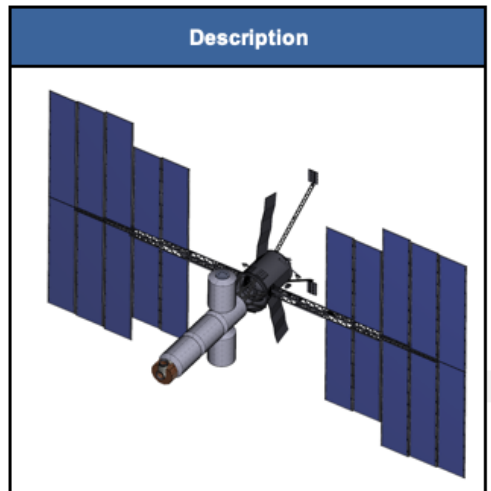

Boeing / Lockheed Martin Modules w/ Hybrid Propulsion

\section{Description}

The Mars Transit Habitat is the primary crew vessel for transportation to Mars. It is designed to support a crew of 4 for up to 1200 days. The habitat will be launched independent of the propulsive element needed for interplanetary travel, requiring element docking, as well as logisitics upload. This assembly is assumed to occur at the Gateway station in cis lunar space ahere it will be configured and refurbished for multiple missions.

\begin{tabular}{|lrr|}
\hline \multicolumn{4}{|c|}{ Design Constraints / Parameters } \\
\hline Maximum Crew Size & \multicolumn{3}{c|}{ 1,200 } & days \\
Max Crewed Mission Duration & Mars Sol & rbit \\
Destination & 383.50 & $\mathrm{~m}^{3}$ \\
Pressurized Volume & 169.40 & $\mathrm{~m}^{3}$ \\
Systems Volume & 123.82 & $\mathrm{~m}^{3}$ \\
Stowage Volume & 90.28 & $\mathrm{~m}^{3}$ \\
Habitable Volume & 101.30 & $\mathrm{kPa}$ \\
Operating Pressure & 21.00 & $\%$ \\
Oxygen Fraction & Closed & \\
Life Support Closure - Water & Closed & \\
Life Support Closure - Air & Aluminum & \\
Habitat Structure & 19.86 & $\mathrm{~m}$ \\
Habitat Overall Length & 17.68 & $\mathrm{~m}$ \\
Habitat Overall Width & 0.00 & $\mathrm{~kg}$ \\
Radiation Protection & 10 & \\
EVA Capability & 2 & \\
Crew per EVA & $440,90,30$ & $\mathrm{~N}$ \\
RCS Engine Type & Hydrazine, & $\mathrm{N} 2 \mathrm{O} 4$ \\
RCS Propellant & 27.18 & $\mathrm{~kW}$ \\
Power Generation & 6.22 & $\mathrm{~kW}$ \\
Energy Storage & 6.22 & $\mathrm{~kW}$ \\
Keep Alive Power (uncrewed) & 247.76 & $\mathrm{~m} 2$ \\
Solar array area & 102.01 & $\mathrm{~m}$ \\
Thermal Radiator Area & $2.25 \%$ & \\
Actual Estimated Loss of Mission & 8.28 & \\
Average TRL & $14.74 \%$ & \\
Mass Growth Allowance (MGA) & $0.00 \%$ & \\
Project Management Reserve (PMR) & & \\
\hline
\end{tabular}

\begin{tabular}{|c|c|c|c|}
\hline & Mass Breakdown & $\begin{array}{c}\text { Launch } \\
\text { Mass }\end{array}$ & $\begin{array}{l}\text { Outfitted } \\
\text { Mass }\end{array}$ \\
\hline \multicolumn{2}{|l|}{ System } & (kg) & $(\mathrm{kg})$ \\
\hline 1.1 & Structures & 26,822 & 26,822 \\
\hline 2.0 & Propulsion & 3,413 & 3,413 \\
\hline 3.0 & Power & 1,405 & 1,405 \\
\hline 4.0 & Avionics & 2,266 & 2,266 \\
\hline 5.0 & Thermal & 2,257 & 2,257 \\
\hline 6.0 & Radiation Protection & - & - \\
\hline 7.0 & ECLSS & 4,157 & 4,157 \\
\hline 8.0 & Crew Systems & 3,254 & 3,254 \\
\hline 9.0 & EVA & 1,116 & 1,116 \\
\hline 10.0 & Research & 764 & 764 \\
\hline 11.0 & Robotics & 943 & 943 \\
\hline \multicolumn{2}{|c|}{ Dry Mass } & 46,396 & 46,396 \\
\hline 12.0 & Stowed Provisions & - & 12,935 \\
\hline 13.0 & Consumables & - & 15,319 \\
\hline 14.0 & Nonpropellant Fluids & 47 & 47 \\
\hline \multicolumn{2}{|c|}{ Inert Mass } & 47 & 28,301 \\
\hline \multicolumn{2}{|c|}{ Subtotal } & 46,443 & 74,697 \\
\hline \multicolumn{4}{|c|}{ Attached Payloads } \\
\hline \multicolumn{4}{|c|}{ Propulsion Stage } \\
\hline 15.0 & Propellant & 934 & 300 \\
\hline 16.0 & Payload Launch Adapter & 3,201 & \\
\hline 17.0 & In-Space Stage Adapter & 1,725 & 1,725 \\
\hline $0.0 \%$ & Project Mgt. Reserve & - & - \\
\hline \multicolumn{2}{|c|}{ Total Gross Mass } & 52,303 & 76,722 \\
\hline
\end{tabular}

Figure A-4. The Boeing Company and Lockheed Martin derived Mars Transit Habitat mass summary.

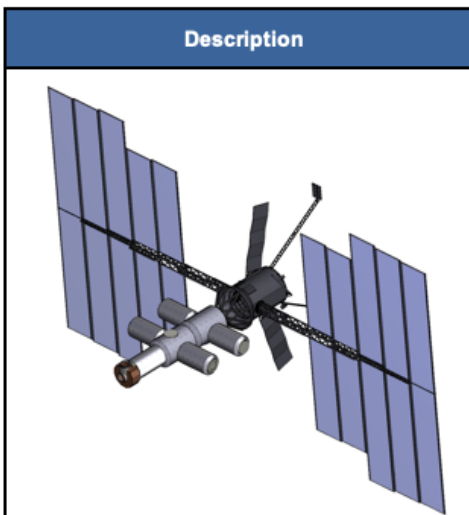

Northrop Grumman Modules w/ Hybrid Propulsion

\begin{tabular}{|c|}
\hline Description \\
\hline $\begin{array}{l}\text { The Mars Transit Habitat is the primary crew vessel for } \\
\text { transportation to Mars. It is designed to support a crew } \\
\text { of } 4 \text { for up to } 1200 \text { days. The habitat will be launched } \\
\text { independent of the propulsive element needed for } \\
\text { interplanetary travel, requiring element docking, as well } \\
\text { as logisitics upload. This assembly is assumed to occur at } \\
\text { the Gateway station in cis-lunar space where it will be } \\
\text { configured and refurbished for multiple missions. }\end{array}$ \\
\hline
\end{tabular}

\begin{tabular}{|c|c|}
\hline \multicolumn{2}{|c|}{ Design Constraints / Parameters } \\
\hline Maximum Crew Size & 4 \\
\hline Max Crewed Mission Duration & 1,200 days \\
\hline Destination & Mars 1 Sol Orbit \\
\hline Pressurized Volume & $348.40 \mathrm{~m}^{3}$ \\
\hline Systems Volume & $176.58 \mathrm{~m}^{3}$ \\
\hline Stowage Volume & $123.80 \mathrm{~m}^{3}$ \\
\hline Habitable Volume & $48.03 \mathrm{~m}^{3}$ \\
\hline Operating Pressure & $101.30 \mathrm{kPa}$ \\
\hline Oxygen Fraction & $21.00 \%$ \\
\hline Life Support Closure - Water & Closed \\
\hline Life Support Closure - Air & Closed \\
\hline Habitat Structure & Aluminum \\
\hline Habitat Overall Length & $20.74 \mathrm{~m}$ \\
\hline Habitat Overall Width & $19.40 \mathrm{~m}$ \\
\hline Radiation Protection & $0.00 \mathrm{~kg}$ \\
\hline EVA Capability & 10 \\
\hline No. of EVAs Out of Hab & 20 \\
\hline RCS Engine Type & $440,90,30 \quad N$ \\
\hline RCS Propellant & Hydrazine, N2O4 \\
\hline Power Generation & $27.15 \mathrm{~kW}$ \\
\hline Energy Storage & $6.20 \mathrm{~kW}$ \\
\hline Keep Alive Power (uncrewed) & $6.20 \mathrm{~kW}$ \\
\hline Solar array area & $247.50 \mathrm{~m}^{2}$ \\
\hline Thermal Radiator Area & $101.92 \mathrm{~m}^{2}$ \\
\hline Actual Estimated Loss of Mission & $2.25 \%$ \\
\hline Average TRL & 7.74 \\
\hline Mass Growth Allowance (MGA) & $14.65 \%$ \\
\hline Project Management Reserve (PMR) & $0.00 \%$ \\
\hline
\end{tabular}

\begin{tabular}{|c|c|c|c|}
\hline & Mass Breakdown & $\begin{array}{c}\text { Launch } \\
\text { Mass }\end{array}$ & $\begin{array}{l}\text { Outfitted } \\
\text { Mass }\end{array}$ \\
\hline System & & (kg) & (kg) \\
\hline 1.1 & Structures & 30,922 & 30,922 \\
\hline 2.0 & Propulsion & 3,265 & 3,265 \\
\hline 3.0 & Power & 1,715 & 1,715 \\
\hline 4.0 & Avionics & 2,588 & 2,588 \\
\hline 5.0 & Thermal & 2,252 & 2,252 \\
\hline 6.0 & Radiation Protection & - & - \\
\hline 7.0 & ECLSS & 4,149 & 4,149 \\
\hline 8.0 & Crew Systems & 3,254 & 3,254 \\
\hline 9.0 & EVA & 1,116 & 1,116 \\
\hline 10.0 & Research & 764 & 764 \\
\hline 11.0 & Robotics & 943 & 943 \\
\hline Dry Mass & & 50,967 & 50,967 \\
\hline 12.0 & Stowed Provisions & - & 12,935 \\
\hline 13.0 & Consumables & - & 15,319 \\
\hline 14.0 & Nonpropellant Fluids & 42 & 42 \\
\hline Inert Mas & & 42 & 28,297 \\
\hline Subtotal & & 51,009 & 79,264 \\
\hline & Attached Payloads & & \\
\hline & Propulsion Stage & & \\
\hline 15.0 & Propellant & 845 & 300 \\
\hline 16.0 & Payload Launch Adapter & 3,517 & \\
\hline 17.0 & In-Space Stage Adapter & 1,830 & 1,830 \\
\hline $0.0 \%$ & Project Mgt. Reserve & - & - \\
\hline \multicolumn{2}{|c|}{ Total Gross Mass } & 57,201 & 81,394 \\
\hline
\end{tabular}

Figure A-5. Northrop Grumman derived Mars Transit Habitat mass summary. 


\section{B. Abbreviations \& ACronyms}

ACO Advanced Concepts Office

CBM Common Berthing Mechanism

CH4 Methane

ECLSS Environmental Control and Life Support System

ESL2 Earth-Sun Lagrange Point 2

EVA Extra-Vehicular Activity

Fig. Figure

GEO Geosynchronous Earth Orbit

ISS International Space Station

LIFE Large Inflatable Fabric Environment

LOX Liquid Oxygen

$\mathrm{kg} \quad$ Kilograms

$\mathrm{kPa} \quad$ Kilopascals

m Meters

$\mathrm{m}^{3} \quad$ Cubic Meters
MGA Mass Growth Allowance

mgt. Management

MIG Mars Integration Group

mT Metric Tons

N Newtons

N2O4 Nitrogen Tetroxide

NDS NASA Docking System

NextSTEP Next Space Technologies Exploration Partnerships

NRO Near Rectilinear Orbit

NTP Nuclear Thermal Propulsion

PMR Project Managers Reserve

RCS Reaction Control System

SEP Solar Electric Propulsion

TMI Trans-Mars-Injection

TRL Technology Readiness Level 


\section{ACKNOWLEDGEMENTS}

The authors would like to thank the Advanced Concepts Office design team for their contribution to this study. That team included Mike Baysinger, Quincy Bean, Pete Capizzo, Olivier Demaneuf, Leo Fabisinski, Sharon Fincher, Jay Garcia, Mark Ibekwe, Alan Philips, Justin Rowe, Steven Sutherlin, Dan Thomas, and the study lead and co-author, David Smitherman.

\section{REFERENCES}

[1] Polsgrove, T., J. Waggoner, D. Smitherman, T. Percy, R. Howard, "Transit Habitat Design for Mars Exploration", Paper No. AIAA-2018-5143, AIAA Space and Astronautics Forum and Exposition, Orlando FL, September 2018.

[2] NASA.gov website: "Moon to Mars, NASA Begins Testing Habitation Prototypes", https://www.nasa.gov/ feature/nasa-begins-testing-habitation-prototypes, visited September 24, 2019.

[3]Simon, M., D. Smitherman, et al, "NASA's Advanced Exploration Systems Mars Transit Habitat Refinement Point of Departure Design,” IEEE Aerospace 2017.

[4] Smitherman, D., T. Polsgrove, J. Rowe, "Safe Haven Configurations for Deep Space Transit Habitats," Paper No. 2017-5285, AIAA Space Forum, Orlando FL, September 2017.

\section{BIOGRAPHY}

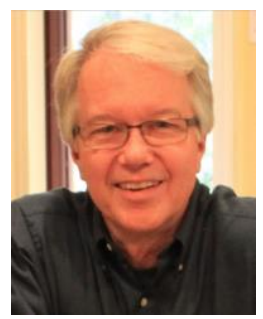

David Smitherman is a technical manager of future projects for the Advanced Concept Office at the NASA Marshall Space Flight Center in Huntsville Alabama. His work focuses on space habitats, lunar and Mars habitation systems, space transportation infrastructures, and overall mission planning. He worked as an architect in the 1980s, as a planner during the redesign of the space station and various space station payloads in the 1990s, and since 1998 has been a study lead for advanced concepts studies including Space Business Parks, New Space Industries, Space Elevators, Solar Power Satellites, Propellant Production Depots, and a wide variety of Deep Space Habitat concepts. Mr. Smitherman has a Master of Science in Space Architecture from the University of Houston (2008), and a Bachelor of Architecture and a Bachelor of Science in Environmental Design from Auburn University (1980). He is a registered architect in the State of Alabama, has a professional certification in Interior Design from the University of Alabama in Huntsville, and holds a national certification from the National Council of Architectural Registration Boards.

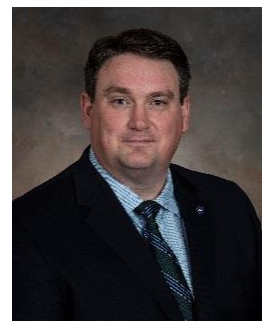

Andrew Schnell is the deputy project manager for NASA's Mars Integration Group. He is a study lead and thermal system designer for Marshall Space Flight Center's Advanced Concepts Office. In over seven years in Advanced Concepts, he has led ACO's design efforts on a variety of conceptual design studies including the Lynx X-Ray Observatory, Mars sample return missions, the Europa lander de-orbit stage, the HabEX telescope, and SLS'S Exploration Upper Stage. He has also contributed thermal designs for deep space habitats, interstellar probes, solar sails, satellites, cubesats, SLS payloads, and ISS experiments. Prior to joining Advanced Concepts, Andrew was a member of NASA's Cryogenic Fluid Management team, where he managed the design and preparation of several cryogenic test articles. He holds a patent for the design of novel foam-rigidized inflatable structures. Andrew is a graduate of Tennessee Technological University. 